\title{
QUE HORAS ELA VOLTA? PERCEPÇÕES DO DISCURSO FÍLMICO POR BLOGUEIRAS FEMINISTAS DO BRASIL
}

\section{Resumo}

O cinema, enquanto produção textual que evidencia formas de agir, pensar e sentir, permite a veiculação de diferentes representações sociais. Este estudo propõe uma análise das percepções de quatro blogueiras feministas brasileiras acerca das mulheres e de suas relações sociais no filme Que horas ela volta? Optou-se por analisar a opinião de espectadoras para verificar como o filme se aproxima e se apropria do contexto socio-histórico, contribuindo para que o cinema se constitua como registro histórico das situações sociais.

Palavras-chave: Cinema, discurso, trabalho doméstico, representação.

\section{Abstract \\ Que horas ela volta? Perceptions of the filmic discourse by feminist bloggers in Brazil \\ Cinema, as a textual production that shows ways of acting, thinking and feeling, allows the propagation of different social representations. This study proposes an analysis of the perceptions of four Brazilian feminist bloggers about women and their social relationships in the film Que horas ela volta? It was decided to analyze the opinion of spectators to verify how the film approaches and appropriates the socio-historical context, making a contribution for the cinema to affirm itself as a historical record of social situations.}

Keywords: Cinema, discourse, domestic employment, representation.

\section{Resumen} de Brasil

Que horas ela volta? Percepciones del discurso fílmico por blogueras feministas

El cine, como producción textual que evidencia formas de actuar, pensar y sentir, permite la difusión de diversas representaciones sociales. Este estudio propone un análisis de las percepciones de cuatro blogueras feministas brasileñas acerca de las mujeres y de sus relaciones sociales en la película Que horas ela volta? Se optó por analizar la opinión de espectadoras para verificar cómo la película se acerca y se apropia del contexto socio-histórico, contribuyendo para que el cine se constituya como registro histórico de las situaciones sociales.

Palabras clave: Cinema, Discurso, Trabajo doméstico, Representación.

Universidade Feevale, Novo Hamburgo, Brasil

Endereço eletrónico: deniseca@feevale.br

Endereço postal: Universidade Feevale, ERS 239, n. 2755, Novo Hamburgo, Rio Grande do Sul, Brasil. CEP: 93525-075

Universidade Feevale, Novo Hamburgo, Brasil

Endereço eletrónico: poli_lopes@gmail.com 


\section{Introdução}

O cinema, para Valim $(2006,289)$, além de testemunhar formas de agir, de pensar e de sentir de uma sociedade, pode ser considerado um agente que estimula transformações, veicula representações e propõe modelos.

Além disso, de acordo com Costa (1989), ele pode ser observado, considerando-se que é técnica, indústria, arte, espetáculo, divertimento e cultura. Nessa reflexão, propõe-se que ele seja considerado, também, como fonte histórica para a discussão de uma questão cara à sociedade brasileira, a relação entre empregadas domésticas, suas patroas e familiares.

Assim, pretende-se, inicialmente apontar um breve histórico e características do cinema, para, então, discutir o filme Que horas ela volta? considerando-se para tanto as representações elaboradas no texto, bem como a opinião de espectadores. Essas opiniões foram retiradas de quatro blogs escritos por mulheres que publicaram sua avaliação sobre o filme - Socialista Morena; Escreva, Lola, Escreva; Geledés e Blogueiras Negras. Evidenciando a forma como esta película foi percebida pelas espectadoras, pretende-se verificar as aproximações da narrativa com o contexto socio-histórico contemporâneo e de que forma dá-se o processo de identidade entre ficção e realidade.

\section{A mulher no cinema brasileiro: um panorama contextual}

O cinema tem por função relatar histórias, com o uso de várias linguagens, entre as quais, a verbal, as imagens, as cores, o figurino, a iluminação, o cenário, enfim, tornando-se complexo pelo fato de coexistirem em uma única produção vários códigos, os quais remetem a possíveis significados.

A narrativa fílmica conduz o espectador a dimensões fictícias ou a situações vivenciadas cotidianamente. Esse instrumento de entretenimento pode levar o indivíduo a incorporar a vida dos personagens como se um fizesse parte da história do outro, «o cinema dá impressão de que é a própria vida que vemos na tela» (Bernardet 1996, 12). O encantamento é grande e causa fascínio, e, por isso, penetra-se nos filmes e não se define uma separação objetiva entre as histórias e as vidas reais.

Busca-se, aqui, analisar as percepções de quatro blogueiras feministas brasileiras acerca da representação da mulher no cinema brasileiro contemporâneo, sendo, para isso, necessário revisitar o contexto histórico-social das produções cinematográficas no país.

Segundo Santos (2015), a produção cinematográfica do Brasil sempre foi influenciada pela situação sociopolítica vigente. Durante os governos de Getúlio Vargas, auxílios dados aos cineastas através do Instituto Nacional do Cinema Educativo (INCE) e do Departamento de Imprensa e Propaganda (DIP) visaram contribuir para a criação de uma nova nacionalidade brasileira (Santos 2015).

Na década de 1950, após a Segunda Guerra Mundial, há uma valorização do exotismo brasileiro, com a produção de filmes representando os índios brasileiros. 
Na década de 1960, o Cinema Novo transita entre a representação de uma ideologia nacionalista e desenvolvimentista e um radical projeto político de esquerda em prol da instauração de um regime socialista (Santos 2015). Este tom alegórico diminui na década de 1970, quando se inicia um processo de reaproximação com o grande público.

Nos anos 1980, a Empresa Brasileira de Filmes S/A (Embrafilme), criada em 1969, começa a dar sinais de desgaste, sendo encerrada no governo Collor (1990-1992). A partir de então, inicia-se o cinema brasileiro contemporâneo (Santos 2015), no qual, segundo Hamburger (2007), surgem novos protagonistas, como negros e pobres; e novos espaços, como favelas e periferias.

Nesta época, especialmente entre 1995 e 1998, o cinema brasileiro viveu sua Retomada, momento em que a produção de filmes foi restabelecida (Nagib 2012). A autora afirma que foi um período de «uma real explosão criativa» (Nagib 2012, 18), ocasionada tanto pelo renascimento cinematográfico quanto pela atmosfera de liberdade política pós 20 anos de ditadura militar.

As produções da época destacaram-se por redescobrir o Brasil, com destaque para o sertão árido do Nordeste - região brasileira que já havia sido destacada durante o Cinema Novo. O sertão revisitado pelos cineastas foi abordado pelo viés cultural, «como uma reunião eufórica com o coração culturalmente rico do país» (Nagib 2012, 18). Esta vertente teve como clímax o filme Central do Brasil, de 1998, de Walter Salles, premiado pelo Festival de Berlim do mesmo ano.

É a esse boom criativo inicial, ocorrido no curto período da Retomada, que se deve relacionar a ascensão das mulheres à direção de filmes, e não ao fenômeno eminentemente comercial mais recente. A prova, em termos numéricos, está no fato de que entre 90 cineastas ativos entre 1994-98, 17 eram mulheres, isto é, aproximadamente $19 \%$, um crescimento significativo quando comparado aos menos de $4 \%$ de presença feminina nos anos pré-Collor. (Nagib 2012, 19)

A partir da Retomada, apesar de crescente, o protagonismo feminino em filmes de longa-metragem no Brasil fica muito aquém do protagonismo masculino e um pouco aquém do protagonismo de ambos os sexos, como mostra a Tabela 1.

Tabela 1.

Distribuição percentual de filmes de longa-metragem por sexo do protagonista no Brasil

\begin{tabular}{lccc}
\hline Sexo do Protagonista I Década & $\mathbf{1 9 9 1 - 2 0 0 0}$ & $\mathbf{2 0 0 1 - 2 0 1 0}$ & Total \\
\hline Homens & 63,50 & 56,33 & 58,00 \\
Mulheres & 13,80 & 18,18 & 17,16 \\
Ambos* & 15,03 & 22,96 & 21,11 \\
Sem informação & 7,67 & 2,53 & 3,73 \\
\hline
\end{tabular}

Fonte: Alves e Coelho $(2015,171)$ 
A partir dos dados apresentados, é possível concordar com Laura Mulvey (1983), que afirma ser o cinema clássico dominado por uma lógica masculina do olhar, mantendo-se ativo um reflexo da cultura patriarcal.

A especificidade do cinema seria o prazer visual e, se tratando de um mundo marcado pela desigualdade sexual, o olhar cinematográfico estaria organizado por uma lógica do ativo/masculino e do passivo/feminino. $\mathrm{O}$ espectador de qualquer sexo, assim, teria uma relação voyeurística com a imagem da mulher na tela, pois os atores também atraíam audiência, mas, as atrizes eram adoradas por ambos os sexos. (Alves e Coelho 2015, 163)

Para opor-se a esta lógica, Alves e Coelho (2015) citam a proposta do «cinema de mulheres», desenvolvida por Lauretis (1984), na qual buscar-se-ia criar outras formas de gerar identificação com as espectadoras, com uma nova linguagem que desloque a figura da mulher como objeto para tomá-la como sujeito da ação.

Desta forma, o «cinema de mulheres» de Lauretis teria como objetivo não apenas gerar a identificação com a espectadora, mas também lhe proporcionar um lugar nele,

incorporando as contradições e singularidades pessoais e políticas presentes nas mulheres dentro e fora da tela. Isso porque a construção social do gênero, da subjetividade e da representação da experiência ocorre tanto em interseção com a raça e com a classe, quanto na - e por meio da - linguagem e cultura. (Alves e Coelho 2015, 166)

Percebe-se, portanto, a necessidade de estudos que indiquem e observem o protagonismo feminino no cinema nacional, como forma de compreender o papel da mulher nas narrativas, assim como a forma como as histórias narradas são percebidas pelas espectadoras.

\section{Que horas ela volta? Um filme sobre mulheres e relações}

O filme Que horas ela volta? é uma produção conjunta entre a Globo Filmes, Gullane Filmes e África Filmes, com distribuição no Brasil pela Pandora Filmes. Tem roteiro e direção de Anna Muylaert e, no elenco principal, Regina Casé (Val), Camila Márdila (Jéssica), Michel Joelsas (Fabinho), Karine Teles (Barbara) e Lourenço Mutarelli (Carlos).

Segundo o site AdoroCinema, o filme destaca as relações entre patrões e empregadas domésticas, com destaque para os limites dessas relações:

A pernambucana Val (Regina Casé) se mudou para São Paulo a fim de dar melhores condições de vida para sua filha Jéssica. Com muito receio, ela deixou a menina no interior de Pernambuco para ser babá de Fabinho, morando integralmente na casa de 
seus patrões. Treze anos depois, quando o menino (Michel Joelsas) vai prestar vestibular, Jéssica (Camila Márdila) lhe telefona, pedindo ajuda para ir a São Paulo, no intuito de prestar a mesma prova. Os chefes de Val recebem a menina de braços abertos, só que quando ela deixa de seguir certo protocolo, circulando livremente, como não deveria, a situação se complica. (AdoroCinema 2015)

A primeira estreia do filme ocorreu em 25 de janeiro de 2015, com o título The Second Mother, durante o Sundance Film Festival 2015 (EUA), no qual a produção foi indicada à categoria de grande prêmio do júri e recebeu prêmio especial do júri pela atuação de Regina Casé e Camila Márdila. A produção recebeu, ao todo, nove prêmios internacionais e três nacionais. O filme também foi eleito para representar o Brasil na disputa por uma vaga na categoria de Melhor Filme Estrangeiro no Oscar 2016 (Globo Filmes 2015), o que não se concretizou.

O lançamento no Brasil ocorreu em 27 de agosto de 2015 e resultou em diversas críticas relacionadas com a produção e a temática abordada (Angiolillo 2015; Ferreira 2015; Lemos 2015; Peirão 2015; Serafim 2015). Estas críticas podem ter relação com a forma como a diretora Anna Muylaert constrói a obra: ela «lançou mão de três grandes diálogos no que tange ao audiovisual: comédia e drama; real e ficção; cinema e televisão. Mesclando diferentes estruturas, ela conquista espaço dentre os mais diferentes públicos» (Serafim 2015). Ao analisar o universo cinematográfico da diretora, Soares e Coração $(2014,117)$ entendem que

Por meio de contrastes e justaposições, o universo do cinema de Anna Muylaert está atrelado, sobretudo, às inconveniências dos próprios temas sociais e dos apelos radicais das experiências culturais atualizadas pelo gênero reportagem em sua articulação com os fatos.

Ao destacar elementos do real, mesmo que de forma discreta, na narrativa (como acontece quando, no início do filme, a personagem Val afirma não entender como as pessoas pegam gelo e colocam a forminha vazia de volta na geladeira), a produção causa uma identificação que pode provocar «risos» ou indignação, pois

Esse incômodo é mais bem avaliado, nos filmes de Muylaert, nos plots corrosivos e nos desenlaces das tramas, quase sempre, provocativamente, «irreais», como se realidade e imaginação fossem indistintas. É nesse aspecto da fantasia (ou da negação do real mais crível) que se desenha um cinema - ainda em gestação, é bom dizer - de forte tom irônico na ação. (Soares e Coração 2014, 117)

O filme, através da personagem Jéssica, retoma a temática do empoderamento feminino iniciado durante a Ditadura Militar no Brasil (1964-1985), quando mulheres assumiram o papel de cineastas e começaram a produzir filmes e também a representar a si mesmas diante das mudanças culturais e comportamentais que ocorreram no período (Silva 2012). 
Além disso, a obra representa a mulher mais humana e menos estereotipada (como a negra mulata em papel de objeto sexual, por exemplo), característica que vem sendo assumida pelo contexto atual do cinema brasileiro (Azevedo 2011). Neste sentido, como aponta Tiago Moreira $(2015,197)$, o cinema nacional vem trazendo novas temáticas acerca da mulher:

A imagem da mulher enquanto objeto de desejo sexual; a exploração sexual feminina; a mulher e seu envolvimento com o crime; o papel social da jovem mulher negra da periferia; a homoafetividade feminina; a mulher e o romantismo no mundo contemporâneo; a mulher jovem e suas questões existenciais; a mulher e a crise matrimonial; a família matriarcal de baixa renda.

Destas questões, percebe-se, também, na narrativa de Que horas ela volta? o destaque à mulher jovem e suas questões existenciais (na história de Jéssica) e a família matriarcal de baixa renda (na relação entre Val e Jéssica).

A partir dessa análise inicial da obra, parte-se para a contextualização histórica da produção e exibição do filme Que horas ela volta? no Brasil, o que será apresentado a seguir.

\section{Percepções a respeito do filme, por blogueiras}

Propõe-se, neste artigo, uma análise da recepção do filme Que horas ela volta? a partir de textos escritos por mulheres e publicados em blogs. Optou-se por este corpus por serem as três personagens principais mulheres, o que permite uma maior identificação entre narrativa e realidade.

Segundo Amaral, Recuero e Montardo (2009), os weblogs (conceito cunhado por Jorn Barger ao unir os termos web mais $\log$ - «arquivo da web») se popularizaram a partir de 1997, com a chegada dos mecanismos de publicação, e, depois, a adição da possibilidade de inserir comentários aos blogs. «Uma das primeiras formas de utilização dos blogs foi a forma de diários. Desta forma, os autores relatavam nos blogs suas experiências, pensamentos e outras formas de expressão pessoal» (Amaral, Recuero e Montardo 2009, 28-29).

Os blogs, segundo Primo e Recuero (2003), são organizados em blocos de textos a partir da data da publicação. Eles podem agregar links para outras fontes, com conteúdos semelhantes ou opostos aos publicados.

Oliveira $(2009,56)$ destaca que

a gratuidade e a amplitude de ferramentas de postagens disponíveis abriu espaço para que pessoas ao redor de todo o mundo se manifestassem através dos blogs, que passaram a tratar dos mais variados assuntos, como educação, política, cultura, entre outros, e até mesmo sendo utilizados apenas como diários pessoais. 
Essa possibilidade de manifestações permite associar os blogs ao espaço público, pois neles é possível o discurso livre (entre outras características), o que possibilita, em determinados momentos e pautas, o surgimento de debates ideológicos, como destaca Rodrigues (2006).

Para este estudo, optou-se pela análise dos textos publicados pelos blogs Socialista Morena; Escreva, Lola, Escreva; Blogueiras Negras e Geledés sobre as impressões das autoras (todas mulheres) a respeito das três personagens femininas do filme: a empregada doméstica Val, sua filha Jéssica e a patroa Bárbara. Estes blogs foram escolhidos devido a sua audiência, principalmente entre mulheres, e sua relevância em outros estudos de gênero.

Este viés permite destacar, como aponta Recuero (2009), que os blogs têm um forte caráter pessoal, mesmo nos que se definem como informativos. Este forte caráter de apresentação de quem escreve faz com que ferramentas como os blogs sejam «apropriadas como formas de expressão do self, espaços do ator social e percebidas pelos demais como tal» (Recuero 2009, 28).

Optou-se pelas três principais personagens femininas por entender que

se os papéis de gênero são socialmente definidos e, como Judith Butler diz, nós os desempenhamos antes de nos darmos conta, no cinema esses papéis são exacerbados. Ou seja, se socialmente «performamos» características de feminino e masculino, no cinema esses estereótipos são intensificados. O cinema clássico narrativo [...] constrói suas personagens baseadas em rótulos e estereótipos, ou seja, em características padronizadas esperadas de cada grupo social: masculinidades e feminilidades, características e padrões de comportamento para os mocinhos, os bandidos, os heróis que, muitas vezes, atores e atrizes já possuem, mas que são especialmente «exagerados» pelas lentes do cinema. (Alves e Coelho 2015, 162)

No post no blog Socialista Morena, a autora Cynara Menezes relata uma experiência pessoal, vivida no supermercado, no mesmo dia em que assistiu ao filme Que horas ela volta? Ela conta que observou a conversa entre a moça do caixa e uma cliente e que, quando foi atendida, questionou a jovem sobre o relacionamento entre as duas, ao que ouviu: «Não, é minha mãe. É que ela trabalha como babá a semana toda, só vai para casa domingo de manhã. E a gente só se vê quando ela vem aqui no supermercado comprar alguma coisa» (Menezes 2015). A situação narrada não era incomum no Brasil (antes da promulgação da lei que regularizou o trabalho doméstico), pois muitas das empregadas domésticas moravam nas casas de seus patrões, e tinham folga somente de quinze em quinze dias, trabalhando da hora do café da manhã até a hora do jantar (Kofes 1994).

Menezes (2015), então, associa o trabalho doméstico brasileiro à escravidão, ao questionar «o que será que um estrangeiro vai pensar ao descobrir este 'segredo' brasileiro, o de que até hoje existe empregada doméstica vivendo em um quartinho dos fundos nas casas da burguesia» (Menezes 2015). Considerando essa 
relação, Kofes (2001) lembra que, no período escravagista brasileiro, os trabalhos manuais eram realizados pelos negros escravizados, conotando esse tipo de trabalho com o aviltamento do indivíduo.

A reflexão de Menezes remete diretamente à história do trabalho doméstico no Brasil. Já no século XIX, as famílias brasileiras mais abastadas deixavam o serviço da casa (limpar e arrumar a casa, lavar as roupas, cuidar das crianças) ao cargo de outras pessoas, normalmente escravos, e, com a abolição da escravatura, de mulheres livres que serviam como ajudantes contratadas. Normalmente, estas moças vinham de famílias pobres buscando não somente um emprego, mas também a possibilidade de um matrimônio (Melo 1998).

Menezes (2015) cita a conquista, por parte das empregadas domésticas, de direitos trabalhistas a partir da aprovação da PEC das Domésticas. ${ }^{1}$ Sobre isso, destacou a vergonha que sentiu de sua identidade nacional, durante a exibição do filme, ao pensar que estrangeiros veriam o Brasil sob a ótica do trabalhador doméstico quase escravo, complementando que

A raiva [...] só não é maior do que a raiva de saber que, não faz muito tempo, houve uma revolta no País quando se deu às empregadas o direito de receber o FGTS (Fundo de Garantia por Tempo de Serviço), como todo trabalhador. Esta gente esperneou por pagar direitos trabalhistas a pessoas que cuidam de seus filhos como se fossem delas! É um misto de ingratidão e descaramento que enoja. (Menezes 2015)

O sentimento de vergonha e o incômodo com as situações que são apresentadas no filme são retratados e também destacados pela jornalista brasileira Nina Lemos, que assistiu ao filme em Berlim, acompanhada por um amigo alemão. Em texto publicado no site da Revista Trip, Lemos destaca:

Estou em um cinema em Kreuzberg, Berlim, e eu sei que é assim na vida real no meu país. A plateia, formada por brasileiros e alemães, dá risos nervosos. Desconfio que os risos nervosos sejam mais de brasileiros como eu, que conhecem bem essa situação e sabem que a escravidão existe no Brasil de uma maneira sinistra. E de uma forma que a gente ainda não foi capaz de acabar. [...] Na saída, encontro uma amiga brasileira, também acompanhada de namorado europeu e ela me diz: «deu um pouco de vergonha». Concordamos que a vergonha é total. (Lemos 2015)

No post do blog Escreva, Lola, Escreva, a autora Lola Aronovich, que também é

1 A Emenda Constitucional n. ${ }^{\circ}$ 66/2012 (PEC das Domésticas) visa estabelecer a igualdade de direitos trabalhistas entre os trabalhadores domésticos e demais trabalhadores urbanos e rurais. A emenda garantiu aos trabalhadores direitos trabalhistas até então não previstos em lei e trouxe mais segurança e reconhecimento social para esses trabalhadores, os quais estavam desamparados legalmente. 
professora da UFC, traz o relato que recebeu de uma jovem, a quem chama apenas de L. (visando manter o anonimato da fonte), no qual a relatante afirma «Sim, eu sou Jéssica. [...] Jéssica foi praticamente meu puro e simples retrato. Nunca me senti tão fortemente identificada com algum personagem como me senti com Jéssica» (Aronovich 2015).

Segundo o relato, L. também é filha de uma empregada doméstica que veio do Nordeste para o Sudeste do País, vivendo muitos anos «naquela gaiola chamada de 'quartinho da empregada'» (Aronovich 2015). A diferença entre a personagem ficcional e sua vida é que, em vez de ser criada por parentes, L. também viveu neste espaço até que sua mãe pôde alugar uma casa.

Esta situação real é destacada pela autora como a representada no filme na personagem Val, que também deixou o Nordeste e, lá, a filha pequena, para trabalhar em casa de família em São Paulo, na qual foi responsável pela criação de Fabinho, filho do casal de patrões Bárbara e Carlos.

Assim, percebe-se que esta migração pode ser entendida como elemento da cultura nacional, a qual tenta unificar os membros da nação em uma única identidade: «uma comunidade imaginada: as memórias do passado; o desejo por viver em conjunto; a preparação da herança» (Hall 2005, 58). O ato de deixar sua casa em busca de uma vida melhor em outro Estado é entendido como comum, rotineiro, sendo incorporado à cultura brasileira, inclusive por estar ligado à história do desenvolvimento econômico do País: à medida que houve o processo de industrialização no Brasil, no início de 1900, muitos jovens saíram do campo e foram para a cidade. Entre estes migrantes, muitos exerciam trabalhos domésticos, algumas vezes em troca de comida e um lugar para morar. (Kuznesof e Higman 1989, in Melo 1998).

L. percebeu o preconceito dos patrões em relação à sua mãe enquanto empregada. Ela era, segundo a leitora, inferiorizada - da mesma forma como acontecia na narrativa fílmica na relação entre Val e os patrões. Esta diferenciação entre ricos e pobres, patrões e empregados, remete à reflexão de Todorov (2003) de que cada sujeito, além de seu eu, conta com o outro com quem se relaciona, do qual se distingue ao perceber que «todos estão lá e eu estou aqui» (Todorov 2003, 3). No filme e no relato de L. a Lola Aronovich (2015), esta percepção fica clara a partir da segregação: Val e Jéssica não podem consumir determinados alimentos nem manter certos hábitos domésticos (como comer à mesa com os patrões) pois são diferentes; L. e sua mãe, como as personagens, deveriam dormir no quarto de empregada, separado dos outros ambientes íntimos da casa, porque este seria o «seu lugar». Em sua pesquisa, Kofes $(2001,167)$ destaca que há «regras que regulam a presença de uma empregada na casa», e cita o cuidado com os alimentos, o cuidado de crianças e o quarto do casal como espaços nos quais a empregada deve ter melhor qualificação profissional. Outra situação que pode ser percebida é aquela discutida por Velho, ao afirmar que «o fato de dois indivíduos pertencerem à mesma sociedade não significa que estejam mais próximos do que se fossem de 
sociedades diferentes» $(1978,124)$. Com isso, observa-se que, ainda que dividam o mesmo espaço, patrões e empregadas ocupam lugares diferentes na geografia doméstica, pois a «hierarquia organizada, mapeia», indicando o lugar de cada um (Velho 1978, 127).

Por ser branca e ter olhos claros, L. destaca ter ouvido muitas vezes

«Nossa, que menina bonita, parece filha de gente rica», a ponto de compreender que foram suas características físicas que a pouparam «de ser rejeitada para ir junto com minha mãe ao emprego. [...] É doentio pensar assim, mas hoje vejo que as pessoas me aceitavam apenas por conta disso. Esse fato é tão assustador, que tenho inúmeras lembranças das pessoas olharem para mim, dizendo que eu era uma menina bonita, logo em seguida perguntavam se eu era filha da patroa e eu dizia que não e apontava para minha mãe. A expressão de encanto das pessoas mudava assustadoramente. Com o tempo fui me acostumando com isso. (Aronovich 2015).

Outra identificação com a personagem Jéssica que L. apontou foi o interesse pelo estudo e a vontade de fugir do ciclo da pobreza, algo que sua mãe não conseguira. Por sua dedicação, relata ter sido aprovada no vestibular em uma universidade federal, ao que a patroa de sua mãe, tal como a personagem Bárbara faz no filme, fez cara de incredulidade e disse que se fosse sua filha, não deixaria morar na capital, ao que L. diz ter questionado (possivelmente em pensamento), pois todos os filhos da patroa tinham estudado na capital, então por que ela não poderia?

O crochê usado por Val para enfeitar os potes de cozinha da casa própria foi o mote do post do blog Blogueiras Negras. O relato de Gabriela Nascimento Ananias inicia com duas histórias relacionadas ao crochê, mas que dizem muito mais: ao recordar das toucas de crochê que a mãe e a tia faziam para sua irmã Aline, também recordou de quando a escola onde a irmã estudava raspou sua cabeça sem autorização dos pais. Sobre este fato, conclui: «Se ela não tivesse cabelo crespo provavelmente isso não ocorreria, porque, é claro, cabelo crespo dos outros é espaço público - toca, revira, até raspa» (Ananias 2015).

Também filha de empregada doméstica, Ananias (2015) conta que frequentava o trabalho da mãe e que «por mais agradável que fosse transitar por um ambiente arejado, iluminado; por mais largos que fossem os sorrisos de 'deixa ela pegar; deixa ela comer', eu sabia que a mesa de jantar era inacessível, que aquela vida cândida e arejada era só de passagem», assim como, no filme, Val e Jéssica fazerem as refeições com os patrões também era inacessível. Tal situação pode ser um exemplo no qual é marcada a distância social existente entre empregada e patroa, que, apesar de dividirem o mesmo espaço social, têm seus territórios claramente demarcados (Kofes 2001).

A autora destaca a frase de Val, «tem coisas que a gente nasce sabendo», dita para a filha Jéssica como um mantra que precisou aprender: 
Eu era a obediente filha da empregada, por isso recebia caixinha de água de coco. Enquanto minha irmã, a da cabeça raspada, recebia áridas broncas de minha avó por ter utilizado o gel de cabelo [a caralha de um gel de cabelo!] do filho da patroa, no banheiro do filho da patroa, enquanto esteve no trabalho com minha avó, também empregada doméstica. Nunca mais ela pode transitar por esse mundo, nem como a neta-da-empregada, justamente porque ela não entendeu tim tim por tim tim o que gente como a gente precisa saber desde que nasce. (Ananias 2015)

A identificação com Jéssica, a autora dedica a suas irmãs Débora e Aline que, segundo ela, sempre se posicionaram em vez de apenas obedecer. Ao final, destaca o empoderamento feminino e negro ao dizer que «A Aline tem um cabelo black incrível, não precisa do maldito gel de cabelo do seu filho, dona fulana!», que não espera mais pelo pai porque sabe que ele não retornará e que sua família formada por mulheres e «todas essas mulheres como nós, permanecemos vivas e agentes ativas da nossa própria história» (Ananias 2015).

O post publicado no blog Geledés traz o relato de Jéssica Moreira, que conta ter assistido ao filme junto com sua mãe que, como a personagem Val, é empregada doméstica. Para a autora, o filme toca na ferida da sociedade brasileira, na qual «a luta de classes é encoberta com a frase 'você é quase da família'» (J. Moreira 2015). Ela explica que este «quase»é

A linha tênue que mantém a empregada na cozinha quando o dia é de festa [...] o andar que separa o quartinho sem ventilação do quarto luxuoso de hóspedes. [...] o presentinho que substitui o salário digno, que sempre fica aquém daquilo que cada babá, empregada doméstica - mensalista ou diarista - realmente deveria receber segundo as leis que regem essas profissões. Mas o «quase» é também a manutenção da terceirização do trabalho doméstico, o mesmo que deveria ser dividido igualmente entre os membros de uma família. (J. Moreira 2015)

Kofes (2001, 139) lembra que as empregadas domésticas circulam em «mundos sociais distintos pela ação combinada de dois modelos de relações: as relações familiares e as relações marcadas pela desigualdade de classe, e as noções de mandar e obedecer». Assim, se estabelece a dominação que mantém relações de cordialidade e certa intimidade entre os envolvidos nesses relacionamentos, ou seja, a empregada nunca será família, pois existem relações trabalhistas envolvidas nesse contexto.

Hoje, no Brasil, a maior parte absoluta de empregados domésticos são mulheres. Segundo pesquisa da Organização Internacional do Trabalho (OIT) realizada em 2013, o país tinha 7,2 milhões de empregados domésticos, sendo 6,7 milhões de mulheres e 504 mil homens. Este mesmo estudo mostra que o Brasil tem a maior população de trabalhadores domésticos do mundo em números absolutos (a partir de comparação entre 117 países) (G1 2013). 
O fato de haver um número muito representativo de mulheres empregadas domésticas é considerado como normal pela sociedade, pois percebe-se ao longo dos tempos que as tarefas de casa são destinadas, quase que exclusivamente, às mulheres, mesmo quando elas exercem outras atividades fora de casa. Ou seja, culturalmente as tarefas de dentro da casa, mesmo que sem remuneração, são destinadas às mulheres, evidenciando, de certa forma, a necessidade de a mulher ter que estar disponível a servir a família, sua ou dos outros. E, de acordo com Sarti (1997), o trabalho feminino doméstico aponta para determinada identidade feminina que está «enredada» nas lides domésticas, o que enfatiza a diferenciação dos gêneros. Kofes $(2001,85)$ reforça a ideia na medida em que afirma que «O fazer doméstico, em nossa sociedade, ainda é uma atribuição feminina». E essa atribuição pode incluir relações de trabalho assalariado, como no caso das empregadas domésticas.

A postura de Val incomodou a mãe da autora Jéssica Moreira, pois a personagem não se posicionava perante os patrões. Em relação a isso, a mãe disse que

«aprendeu desde cedo que não se pode ser passiva diante das adversidades da vida» e exemplificou contando que «uma das patroas pediu para que ficasse até às sete da noite para limpar a casa. «Se o que você me pagasse valesse a pena, eu até ficava, né?» (J. Moreira 2015)

Ao falar sobre o filme, a autora (2015) também mencionou a PEC das Domésticas, que

trouxe uma série de direitos a essas trabalhadoras, como a garantia de salário nunca inferior ao mínimo (hoje $\mathrm{R} \$ 788$ ) e jornada de trabalho nunca superior a 8 horas diárias. Em maio desse ano, o Senado aprovou outros sete benefícios, que vão de contrato de trabalho e multa em caso de demissão. O texto foi sancionado em junho pela presidenta Dilma Rousseff. (J. Moreira 2015)

Outro ponto destacado por Jéssica Moreira são as memórias de sua mãe, as quais foram avivadas pelo filme, memórias de luta, cansaço e de dor. Segundo a autora, Luiza, sua mãe, afirmou, após o filme:

Trabalhar em casa de família não é bom negócio para ninguém. Por mais legal que a família seja com a gente, a gente nunca é valorizada completamente. Nunca paga por tudo que trabalhamos. A gente faz demais dentro de uma casa. Você faz tudo por muito pouco. Tem dia que acordo e não tenho vontade de ir. (J. Moreira 2015)

Ao mexer com a memória das autoras dos textos publicados pelos quatro blogs analisados, o filme Que horas ela volta? atinge sua memória coletiva, a qual é estruturada a partir da memória individual de cada autora unida a 
pontos de referência, como outras histórias narradas a elas, tradições e regras de interações.

O momento vivido é que define como a memória de um grupo social será estruturada - o que se vai gravar e transmitir, o que se vai esquecer e silenciar. Este é um processo de seleção que pode ser um movimento interno e voluntário, mas pode ser também provocado e imposto por grupos dominantes que fazem da memória um poder a ser manipulado - daí a promoção do esquecimento e o silenciamento. (Cunha 1999, 2)

Quando se fala em memória coletiva relacionada a sofrimento e dificuldades vividas, pode-se perceber o desejo de esquecerem o passado, o que não acontece nos textos analisados. Ao trazer à tona relatos vividos (ou conhecidos), as autoras demonstram que estas memórias estão vivas e agindo sobre suas decisões presentes. L., que narra sua história no blog Escreva, Lola, Escreva, por exemplo, afirma trabalhar constantemente para que sua mãe não precise mais trabalhar como doméstica e viver na casa de outras pessoas.

Os posts também identificam, nas histórias relatadas, o mesmo objetivo da personagem Val, citado pelo site Adoro Cinema - dar melhores condições de vida para sua filha Jéssica -, como o objetivo das mães e mulheres trabalhadoras domésticas mencionadas nos textos.

Confirma-se, neste estudo, a reflexão de Pollak (1989) de que o filme é o melhor suporte para o enquadramento da memória, pois este, além de dirigir as capacidades cognitivas, capta as emoções e traz o assunto à tona, forçando uma melhor compreensão do acontecimento.

Os relatos apresentados nos quatro blogs analisados corroboram o pensamento da cineasta Anna Muylaert, responsável pelo roteiro do filme. Inicialmente, ela acreditava que a personagem Jéssica era uma utopia mas, após o lançamento do filme no Brasil, afirmou que «conheceu diversos jovens que se identificaram com a história e diziam ser a primeira pessoa da família a entrar na universidade» (Revista Fórum 2016).

\section{Considerações Finais}

Ao término dessa reflexão, verifica-se que o cinema se constitui como um texto cultural, o qual estimula o pensar a respeito de uma temática abordada, mas não somente isso, também evidencia, socialmente, determinadas situações cuja importância é evidente.

O filme Que horas ela volta? se configura como um momento para pensar a respeito das relações sociais existentes entre empregadas, empregadoras, familiares, vivências e desejos desses indivíduos. Por ter protagonismo feminino, acaba gerando uma identificação maior entre as mulheres, o que justifica a escolha do corpus de análise. 
No presente artigo, pode-se verificar que os posts das quatro blogueiras feministas selecionadas apontam para um descontentamento por parte dos empregados domésticos e revelam a falta de valorização desses empregados, a desigualdade social refletida dentro da casa, pelos espaços ocupados por esses empregados (quartos são chamados de cubículos e gaiolas, por exemplo), a diferenciação no consumo de determinados alimentos, que são de exclusividade da família, entre outras situações.

Esse descontentamento é apontado no filme, o qual, a partir da discussão entre mãe e filha, revela que a desigualdade social marcada nas relações entre patrões e empregados não é aceita pela personagem mais jovem, a qual percebe claramente essas diferenças e tenta, ao seu modo, revertê-las.

No Brasil, o trabalho doméstico sofre pela falta de valorização social, e, até há três anos, também não possuía uma legislação que assegurasse o direito desses trabalhadores. A aprovação da PEC das Domésticas é apontada por duas blogueiras, Cynara Menezes e Jéssica Moreira. Menezes (2015) cita a conquista de direitos trabalhistas mas também destacou a vergonha que sentiu, enquanto brasileira, ao perceber que estrangeiros veriam, no filme, uma sociedade brasileira que ainda conta com um trabalhador doméstico quase escravo. Já Jéssica Moreira (2015) destaca os benefícios da PEC e ressalta que ela foi sancionada por uma presidenta, Dilma Rousseff, o que pode ser entendido como uma associação: uma mulher valorizou e ajudou mulheres.

O relato de Ananias no blog Blogueiras Negras toca mais fortemente na questão do feminismo e do protagonismo feminino, assuntos que estão em alta atualmente. A autora compara, inclusive, a sua postura perante as situações vividas pela mãe e avó empregadas domésticas com a de suas irmãs Débora e Aline, a quem destaca por se posicionarem como agentes ativas da própria história.

O filme, então, estrutura-se como pano de fundo para a discussão de questões sociais presentes no país, as quais não eram tidas como importantes até há pouco tempo. Evidentemente, não se imagina que essa película vá esgotar o assunto, pelo contrário, ela tornou-se um momento importante para desvelar certas questões que se tornaram recorrentes na sociedade brasileira, mas há muito que se pensar, ainda, a respeito não só da relação empregados e patrões mas também da relação empregados domésticos e sociedade brasileira.

\section{Referências}

AdoroCinema. 2015. «Que horas ela volta?» AdoroCinema.com. Disponível em http://www. adorocinema.com/filmes/filme-231230/. [Consultado em 15 de agosto de 2016].

Alves, Paula, e Paloma Coelho. 2015. «Discursos, performatividades e padrões visuais no cinema». ACENO - Revista de Antropologia do Centro-Oeste 2(3): 159-176. Disponível em http://www.periodicoscientificos.ufmt.br/ojs/index.php/aceno/article/view/2529/ pdf. [Consultado em 6 de setembro de 2016]. 
Amaral, Adriana, Raquel Recuero, e Sandra Portella Montardo. 2009. «Blogs: mapeando um objeto». In: Blogs.Com: estudos sobre blogs e comunicação, organizado por Adriana Amaral, Raquel Recuero, e Sandra Portella Montardo, 27-53. São Paulo: Momento Editorial.

Ananias, Gabriela Nascimento. 2015. «Não é uma crítica de cinema, é sobre crochê», BlogueirasNegras.org, 30 de setembro. Disponível em http://blogueirasnegras.org/2015/09/30/ nao-e-uma-critica-de-cinema-e-sobre-croche/. [Consultado em 15 de agosto de 2016].

Angiolillo, Francesca. 2015. «A indulgência do filme Que Horas Ela Volta?, de Anna Muylaert». Folha de São Paulo, 20 de setembro. Disponível em http://www1.folha.uol.com. br/ilustrissima/2015/09/1683170-a-indulgencia-do-filme-que-horas-ela-volta-de-anna-muylaert.shtml. [Consultado em 15 de agosto de 2016].

Aronovich, Lola. 2015. «Guest post: eu sou Jessica». Escreva, Lola, Escreva, 29 de outubro. Disponível em http://escrevalolaescreva.blogspot.com.br/2015/10/guest-post-eu-soujessica.html. [Consultado em 15 de agosto de 2016].

Azevedo, Paula Tatiane. 2011. Até onde você iria por um filho? Representações de gênero e maternidade no cinema. Trabalho de Conclusão de Curso (Especialização em Educação, Sexualidade e Relações de Gênero). UFRGS/Programa de Pós-Graduação em Educação.

Bernardet, Jean-Claude. 1996. O que é cinema. São Paulo: Brasiliense.

Costa, Antonio. 1989. Compreender o cinema. 2. ${ }^{\text {a }}$ ed. São Paulo: Globo.

Cunha, Magali do Nascimento. 1999. «Contra todo silenciamento e esquecimento - Memória de uma experiência de contra-informação religiosa». In: Anais do ALAIC 1999. São Paulo: ALAIC. Disponível em www.eca.usp.br/associa/alaic/Congreso1999/14gt/ MagaliNascimento.doc\#_ftn1. [Consultado em 1 de agosto de 2016].

Ferreira, Wilson. 2015. «Que Horas Ela Volta? exibe luta de classes padrão exportação da Globo Filmes». GGN, 7 de novembro. Disponível em http://jornalggn.com.br/blog/ wilson-ferreira/que-horas-ela-volta-exibe-luta-de-classes-padrao-exportacao-da-globo-filmes. [Consultado em 15 de agosto de 2016].

G1. 2013. «Brasil tem o maior número de domésticas do mundo, diz OIT». G1.globo.com, 9 de janeiro. Disponível em http://g1.globo.com/concursos-e-emprego/noticia/2013/01/ brasil-tem-o-maior-numero-de-domesticas-do-mundo-diz-oit.html. [Consultado em 15 de agosto de 2016].

Globo Filmes. 2015. «Que horas ela volta? Filme é selecionado para disputar vaga de Melhor Filme Estrangeiro no Oscar 2016». GloboFilmes.globo.com, 10 de setembro. Disponível em http://globofilmes.globo.com/noticia/que-horas-ela-volta-12/. [Consultado em 15 de agosto de 2016].

Hall, Stuart. 2005. A Identidade Cultural na Pós-Modernidade. Rio de Janeiro: DP\&A.

Hamburger, Esther. 2007. «Violência e Pobreza no Cinema Brasileiro Recente». Revista Novos Estudos 78: 113-128. Disponível em http://www.scielo.br/pdf/nec/n78/11.pdf. [Consultado em 6 de setembro de 2016].

Kofes, Suely. 1994. «Experiências sociais, interpretações individuais: histórias de vida, suas possibilidades e limites». Cadernos Pagu (3): 117-141. Disponível em https://periodicos. sbu.unicamp.br/ojs/index.php/cadpagu/article/view/1725

Kofes, Suely. 2001. Mulher, mulheres: identidade, diferença e desigualdade na relação entre patroas e empregadas. Campinas, SP: Editora da Unicamp.

Lauretis, Teresa. 1984. Alice Doesn't: Feminism, Semiotics, Cinema. Bloomington, IN: Indiana University Press.

Lemos, Nina. 2015. «Assistir a 'Que Horas Ela Volta' na Europa». Revista Trip, 15 de setembro. Disponível em http://revistatrip.uol.com.br/tpm/assistir-a-que-horas-ela-voltana-europa-passar-vergonha-pelo-brasil. [Consultado em 15 de agosto de 2016. 
Melo, Hildete Pereira. 1998. «O serviço doméstico remunerado no Brasil: de criadas a trabalhadoras», Texto para discussão $n^{\circ} 565$. Rio de Janeiro: IPEA. Disponível em http://repositorio.ipea.gov.br/bitstream/11058/2423/1/td_0565.pdf. [Consultado em 12 de setembro de 2016].

Menezes, Cynara. 2015. «Que Horas Ela Volta? e os patrões que não querem pagar FGTS a quem cria seus filhos». Socialista Morena, 14 de setembro. Disponível em http://www. socialistamorena.com.br/que-horas-ela-volta/. [Consultado em 15 de agosto de 2016].

Moreira, Jéssica. 2015. "Que horas ela volta? e os sonhos da minha mãe para mim». Geledés - Instituto da Mulher Negra, 27 de setembro de 2015. Disponível em: <http://www. geledes.org.br/que-horas-ela-volta-e-os-sonhos-de-minha-mae-para-mim/>. [Consultado em 15 de agosto de 2016.

Moreira, Tiago de Almeida. 2015. «Representações sobre a mulher no cinema brasileiro contemporâneo». GeoGraphos 6: 180-201. Disponível em http://hdl.handle.net/10045/48889. [Consultado em 15 de agosto de 2016].

Mulvey, Laura. 1983. «Prazer Visual e Cinema Narrativo». In: A Experiência do Cinema: antologia, organizado por Ismail Xavier, 437-454. Rio de Janeiro: Graal.

Nagib, Lucia. 2012. «Além da diferença: a mulher no cinema da retomada». Devires 9(1): 14-29. Disponível em http://www.fafich.ufmg.br/devires/index.php/Devires/article/ view/208/77. [Consultado em 5 de setembro 2016].

Oliveira, Rosa Meire Carvalho. 2009. O ciberespaço e a escrita de si na contemporaneidade: repete o velho, o novo blog? In: Blogs.Com: estudos sobre blogs e comunicação, organizado por Adriana Amaral, Raquel Recuero, e Sandra Portella Montardo. São Paulo: Momento Editorial.

Peirão, Solange. 2016. «Que horas ela volta? Só a gente que vive é que sabe». Revista Fórum, 27 de fevereiro. Disponível em http://www.revistaforum.com.br/2016/02/27/que-horas-ela-volta/. [Consultado em 15 de agosto de 2016.

Pollak, Michael. 1989. «Memória, Esquecimento, Silêncio». Estudos Históricos, 2(3): 3-15.

Primo, Alex, e Raquel Recuero. 2003. «Hipertexto cooperativo: uma análise da escrita coletiva a partir dos Blogs e da Wikipédia». Revista Famecos: mídia, cultura e tecnologia 1(22): 54-65. Disponível em http://revistaseletronicas.pucrs.br/ojs/index.php/revistafamecos/article/viewFile/3235/2496. Consultado em 15 de agosto de 2016].

Recuero, Raquel. 2009. «Os Elementos das Redes Sociais na Internet». In: Redes sociais na internet, Raquel Recuero, 25-55. Porto Alegre: Sulina.

Rodrigues, Catarina. 2006. Blogs e a fragmentação do espaço público. Covilhã: Universidade da Beira Interior. Disponível em http://www.labcom-ifp.ubi.pt/ficheiros/rodrigues-catarina-blogs-fragmentacao-espaco-publico.pdf. [Consultado em 15 de agosto de 2016].

Santos, Jeferson Reis. 2015. «'Que horas ela volta?' e 'doméstica' - uma análise da representação do trabalho doméstico feminino remunerado no cinema brasileiro contemporâneo». Cadernos de Gênero e Diversidade 1(1): 334-349. Disponível em http://www. portalseer.ufba.br/index.php/cadgendiv/article/view/16333/10993. [Consultado em 6 de setembro de 2016].

Sarti, Cynthia Andersen. 1997. «Os filhos dos trabalhadores: quem cuida das crianças?» In: Trabalho, saúde e gênero: na era da globalização, organizado por Eleanora Menicucci Oliveira, e Lucila Scavone, 51-60. Goiânia: AB.

Serafim, Victória. 2015. «Os discursos e a repercussão de Que Horas Ela Volta?» Ciências da Linguagem Jorwiki, 8 de novembro Disponível em http://www.usp.br/cje/jorwiki/exibir. php?id_texto=339. [Consultado em: 15 de agosto de 2016].

Silva, Alberto. 2012. «Quando as mulheres filmam: História e gênero no cinema dos anos da ditadura».Esboços 19(27):14-31. DOI:https://doi.org/10.5007/2175-7976.2012v19n27p14 
Soares, Rosana de Lima, e Claudio Coração. 2014. «Retrato invulgar do cotidiano e subversão de gêneros no cinema de Anna Muylaert». Revista Novos Olhares 3 (2): 113-124. Disponívelemhttp://www.revistas.usp.br/novosolhares/article/view/90208/92916.[Consultado em 15 de agosto de 2016].

Todorov, Tzvetan. 2003. A Conquista da América: A Questão do Outro. São Paulo: Martins Fontes.

Valim, Alexandre Busko. 2006. Imagens Vigiadas: uma história social do cinema no alvorecer da Guerra Fria, 1945-1954. Tese de doutoramento em História Social, Universidade Federal Fluminense, Niterói, Rio de Janeiro.

Velho, Gilberto. 1978. «Observando o familiar». In: A aventura sociológica, objetividade, paixão, improviso e método na pesquisa social, organizado por Edson de Oliveira Nunes. Rio de Janeiro: Jorge Zahar.

Denise Castilhos de Araujo. Doutora em Comunicação Social, docente e pesquisadora do Programa processos e manifestações culturais, e dos cursos de Comunicação Social na Universidade Feevale.

Endereço eletrónico: deniseca@feevale.br

Poliana Lopes. Mestre e doutoranda pelo programa de processos e manifestações culturais da Universidade Feevale.

Endereço eletrónico: poli_lopes@gmail.com

Artigo recebido a 31 de maio de 2017 e aceite para publicação a 6 de outubro de 2017. 
